\title{
Niclosamide suppresses T-cell acute lymphoblastic leukemia growth through activation of apoptosis and autophagy
}

\author{
FANG-LIANG HUANG ${ }^{1-3}$, SHENG-JIE YU ${ }^{4}$, EN-CHIH LIAO ${ }^{3,5}$, \\ LONG-YUAN LI ${ }^{6}$, PEI-WEN SHEN ${ }^{7}$ and CHIA-LING LI ${ }^{1}$ \\ ${ }^{1}$ Children's Medical Center, Taichung Veterans General Hospital, Taichung 40705; ${ }^{2}$ Department of Physical Therapy, \\ Hungkuang University, Taichung 43302; ${ }^{3}$ Institute of Biomedical Sciences, MacKay Medical College, \\ New Taipei City 25245; ${ }^{4}$ Department of Medical Education and Research, Kaohsiung Veterans General Hospital, \\ Kaohsiung 813414; ${ }^{5}$ Department of Medicine, MacKay Medical College, New Taipei City 25245; \\ ${ }^{6}$ Department of Life Sciences, National Chung Hsing University, Taichung 402; ${ }^{7}$ Department of Anesthesiology, \\ Kaohsiung Veterans General Hospital, Kaohsiung 813414, Taiwan, R.O.C.
}

Received July 10, 2021; Accepted November 26, 2021

DOI: $10.3892 /$ or.2021.8241

\begin{abstract}
T-cell acute lymphoblastic leukemia (T-ALL) is a common pediatric malignancy, characterized by the abnormal presence of immature T-cell progenitors. Conventional treatments for T-ALL fail to prevent or cure the disease, with a high-risk of recurrence after the first remission. Thus, medical options are in demand to develop novel therapies for patients suffering with T-ALL. Niclosamide, a traditional oral anti-helminthic drug, has been reported to be a potential anticancer agent that regulates intracellular signaling pathways. Few studies have yet investigated the effects of niclosamide on the development of T-ALL. Here, the present study aimed to investigate the anti-leukemia effects of niclosamide on T-ALL. We first hypothesized that the suppressive effects of niclosamide on the tumor growth of T-ALL are exerted by regulating autophagy and apoptosis. Following niclosamide treatment, T-ALL cell viability was evaluated using MTT assay, and apoptosis with Annexin V/propidium iodide staining. In T-ALL cells treated with niclosamide, changes in apoptosis- and autophagy-related proteins were analyzed by western blotting. In addition, in an in vivo model, T-ALL xenograft mice were used to study the anti-leukemia effects of niclosamide. The results showed that niclosamide significantly reduced the viability of Jurkat and CCRF-CEM T-ALL cells in both a dose- and time-dependent manner. Niclosamide significantly activated the early and late phases of apoptosis in Jurkat (at $2 \mu \mathrm{M}$ ) and CCRF-CEM cells (at $1 \mu \mathrm{M}$ ).
\end{abstract}

Correspondence to: Dr Chia-Ling Li, Children's Medical Center, Taichung Veterans General Hospital, 1650 Taiwan Boulevard Sect. 4, Taichung 40705, Taiwan, R.O.C.

E-mail: lingboxer@gmail.com

Key words: acute lymphoblastic leukemia, niclosamide, apoptosis, autophagy, xenograft
Furthermore, niclosamide upregulated protein expression of cleaved caspase-3 and LC3B, while downregulated those of Bcl-2 and p62, in a dose-dependent manner in both Jurkat and CCRF-CEM cells. The in vivo results showed that niclosamide treatment significantly suppressed tumor growth and the disease progression in T-ALL xenograft mice by activating cleaved caspase- 3 and LC3B. We conclude that niclosamide plays an anti-leukemia role, and that it represents a novel approach for the treatment of T-ALL.

\section{Introduction}

Acute lymphoblastic leukemia (ALL) is the most common hematologic malignant disorder of children. It is divided into two subtypes: B-cell acute lymphoblastic leukemia (B-ALL) and T-cell acute lymphoblastic leukemia (T-ALL) (1). Among adults, B-ALL constitutes $75 \%$ of cases, with T-ALL constituting the other $25 \%(1,2)$. In childhood ALL, T-ALL accounts for $15 \%$ of pediatric ALL cases (3). In Taiwan 200 new cases of ALL are diagnosed annually. These patients develop comorbidities including hypothyroidism, obesity, metabolic syndrome and subclinical cardiac dysfunction (4). In recent years, several new drugs such as resveratrol, everolimus and selumetinib have been used to treat ALL, and compared with previously used drugs, they cause higher complete remission and lower drug toxicity (5-8). However, due to drug resistance and relapse, the prognosis of patients with T-ALL is still not satisfactory. Therefore, developing a new strategy to treat recurrent ALL and decrease the side effects has become an important issue.

Niclosamide has been a traditional oral anti-helminthic drug for about half a century, with FDA-approval for treating parasitic infections worldwide. According to previous reports, niclosamide is relatively safe and non-toxic to mammals (oral $\mathrm{LD}_{50}$ of $>5 \mathrm{~g} / \mathrm{kg}$ in rats) $(9,10)$. A previous study reported that an abnormally low ratio of Bcl-2-associated $\mathrm{X}$ protein (Bax)/B-cell lymphoma 2 (Bcl-2), and a spontaneous loss of caspase-3 processing are positively correlated with the relapse 
rate of childhood ALL (11). Therefore, the metabolic pathway that regulates apoptosis may be a useful target to prevent the relapse of ALL. It was also reported that niclosamide regulates multiple signaling pathways, including nuclear factor $(\mathrm{NF})-\kappa \mathrm{B}, \mathrm{Wnt} / \beta$-catenin, mechanistic target of rapamycin complex 1 (mTORC1), signal transducer and activator of transcription 3 (STAT3) and Notch, thereby achieving its anticancer actions (12). Niclosamide, through activation of these apoptotic pathways, reduces the expression of $\mathrm{Ki}-67$ cells and p-STAT3 ${ }^{\text {Try705 }}$ in melanoma. Furthermore, it can inhibit metastasis in lung cancer (13). In osteosarcoma, niclosamide was found to inhibit osteosarcoma cell proliferation through cell apoptosis and inhibition of cell cycle progression. In the mouse xenograft tumor model of human osteosarcoma cells, niclosamide inhibited tumor growth (14). On the other hand, autophagy is an evolutionary process in cells. This process involves the transport of damaged organelles, misfolded proteins and other macromolecular substances to lysosome for degradation. In cancer, cells are self-phagocytic. Reduced autophagy inhibits degradation of damaged organelles and increases oxidative stress. These changes lead to cancer development $(15,16)$. Previous studies have shown that glucocorticoids are useful in treating B-ALL by inducing cellular autophagy and causing cell death $(17,18)$. In the ALL Jurkat cell model, Timosaponin AIII was found to induce cell apoptosis and autophagy for its antitumor action (19). Autophagy is therefore widely used in treating ALL. Niclosamide inhibits the growth of colorectal cancer both in vitro and in vivo by inhibiting Wnt signaling through internalizing Wnt receptors and degrading Dishevelled 2 and $\beta$-catenin proteins of the Wnt signaling pathway. Niclosamide-induced inhibition of Wnt signaling was found to be regulated by autophagosome (20). Apoptosis and autophagy hence play important roles in regulating the development of leukemia. As demonstrated above, niclosamide displays anticancer activity in different cancers. However, few reports have been published concerning the effects of niclosamide on T-ALL development. We hypothesized here that niclosamide has anticancer effects on T-ALL. Niclosamide likely acts to ameliorate T-ALL in different ways, such as autophagy and apoptosis. To this end, the anticancer effects of niclosamide on T-ALL were investigated in the present study.

\section{Materials and methods}

Cells and drug treatments. Human T-ALL cell lines Jurkat and CCRF-CEM (obtained from the American Type Culture Collection; ATCC), were kept at $37^{\circ} \mathrm{C}$ in RPMI-1640 medium (Gibco; Thermo Fisher Scientific, Inc.) supplemented with $10 \%$ heat-inactivated fetal bovine serum (FBS; HyClone; GE Healthcare Life Sciences), $1 \mathrm{mM}$ sodium pyruvate (HyClone; GE Healthcare Life Sciences), $100 \mathrm{U} / \mathrm{ml}$ penicillin, and $100 \mu \mathrm{g} / \mathrm{ml}$ streptomycin (Invitrogen; Thermo Fisher Scientific, Inc.), and maintained in a humidified atmosphere containing 95\% air and $5 \% \mathrm{CO}_{2}$. Cells were treated with niclosamide (ACROS Organics ${ }^{\mathrm{TM}}$ ) at different doses and time courses.

Cell viability assay. The MTT assay was performed to assess the effects of niclosamide on the viability of T-ALL cells. Thiazolyl blue tetrazolium bromide (Sigma-Aldrich; Merck
$\mathrm{KGaA}$ ) was prepared from a stock concentration of $5 \mathrm{mg} / \mathrm{ml}$ in PBS, and then diluted with RPMI-1640 medium to a working concentration of $0.5 \mathrm{mg} / \mathrm{ml}$. To evaluate the dose-dependent effects of niclosamide, Jurkat and CCRF-CEM cells were seeded at a density of $1 \times 10^{5}$ cells/well in a 96-well cell culture plate. They were treated at $37^{\circ} \mathrm{C}$ for $24 \mathrm{~h}$ with either the vehicle control (DMSO) or different doses of niclosamide $(0.125,0.25$, $0.5,1.0,2.0$ and $4.0 \mu \mathrm{M})$. To evaluate the time-dependent effects of niclosamide, Jurkat cells were treated with vehicle control (DMSO) or niclosamide $(2 \mu \mathrm{M})$ for 24,48 , and $72 \mathrm{~h}$. CCRF-CEM cells were also treated with vehicle control (DMSO) or niclosamide $(1 \mu \mathrm{M})$ for 24,48 and $72 \mathrm{~h}$. After incubation, thiazolyl blue tetrazolium bromide $(0.5 \mathrm{mg} / \mathrm{ml})$ was then added, and cells were incubated for $2 \mathrm{~h}$ in dark. Formazan crystals were dissolved in DMSO, and the absorbance was measured at $570 \mathrm{~nm}$ using an ELISA reader (BioTek Synergy HT). Each experiment was conducted three times.

Flow cytometry of $\mathrm{Ki}-67$ staining. To assess the cell proliferation, Jurkat and CCRF-CEM cells were seeded at a density of $2 \times 10^{6}$ cells/well in a 24 -well cell culture plate, while Jurkat cells were treated with either vehicle control (DMSO) or niclosamide (1.0, 2.0 and 4.0 $\mu \mathrm{M})$; and CCRF-CEM cells were treated with either vehicle control (DMSO) or niclosamide $(0.5,1.0$ and $2.0 \mu \mathrm{M})$ at $37^{\circ} \mathrm{C}$ for $24 \mathrm{~h}$. After niclosamide treatment, the cells were harvested and fixed with $70 \%$ ethanol and stored at $-20^{\circ} \mathrm{C}$. Then, the cells were washed and stained with Alexa Fluor ${ }^{\circledR} 488$ anti-human Ki-67 antibody (cat. no. 151204, 1:200 dilution; BioLegend $\left.{ }^{\circledR}\right)$ in the dark for 30 min. The mean fluorescence intensity (MFI) of Ki-67 expression was recorded using a FACSCalibur flow cytometer using CellQuest software (version 5.2; BD Biosciences).

Apoptotic assays. Jurkat and CCRF-CEM cells were seeded at a density of $5 \times 10^{5}$ cells/well in a 24 -well cell culture plate; Jurkat cells were treated with either the vehicle control (DMSO) or niclosamide $(2 \mu \mathrm{M})$ while CCRF-CEM cells were treated with vehicle control (DMSO) or niclosamide $(1 \mu \mathrm{M})$ at $37^{\circ} \mathrm{C}$ for $24 \mathrm{~h}$. After incubation, the cells were washed twice with PBS, and then labeled with Annexin V-fluorescein isothiocyanate and propidium iodide (PI) according to the manufacturer's instructions (Elabscience). Fluorescence intensities were measured with flow cytometry. Each experiment was performed in duplicate, for at least three times independently.

Cytosolic and mitochondrial protein isolation. Cytosolic and mitochondrial protein fractions were extracted from the vehicle-treated or niclosamide-treated Jurkat or CCRF-CEM cells using the Mitochondria/Cytosol Fractionation Kit (cat. no. K256-100, BioVision Inc.). Briefly, $1 \times 10^{7}$ cells were harvested, washed and centrifuged at $600 \mathrm{x} \mathrm{g}$ for $5 \mathrm{~min}$ at $4^{\circ} \mathrm{C}$. Next, the cells were resuspended in cytosol extraction buffer mix, incubated on ice for $10 \mathrm{~min}$, and homogenized on ice using the XL-2020 Sonicator Ultrasonic Processor (Heat Systems Inc.) The homogenate was centrifuged at $700 \mathrm{x} g$ for $10 \mathrm{~min}$ at $4^{\circ} \mathrm{C}$. The supernatant was collected and centrifuged at $10,000 \mathrm{x} \mathrm{g}$ for $30 \mathrm{~min}$ at $4^{\circ} \mathrm{C}$. That supernatant was used as the cytosolic fraction. The pellet was resuspended in mitochondrial extraction buffer mix, vortexed for $10 \mathrm{sec}$, and used as the mitochondrial fraction. 
Western blot analysis. Autophagy- and apoptosis-related proteins were determined using western blot analysis. Jurkat and CCRF-CEM cells were seeded at a density of $1.5 \times 10^{6}$ cells/well in a 12 -well cell culture plate. Jurkat cells were treated with either vehicle control (DMSO) or niclosamide $(1.0,2.0$ and $4.0 \mu \mathrm{M})$, and CCRF-CEM cells were treated with either vehicle control (DMSO) or niclosamide $(0.5,1.0$ and $2.0 \mu \mathrm{M})$ at $37^{\circ} \mathrm{C}$ for $24 \mathrm{~h}$. After niclosamide treatment, the cells were harvested and protein expression levels were evaluated with western blotting using appropriate antibodies. Antibodies for apoptosis protein markers (Bcl-2, cleaved caspase-3, caspase-3 and cytochrome $c$ ) and autophagy protein markers (LC3B, p62 and ATG5) were used in experiments. In brief, cells were first washed with PBS before collection. Cells were lysed in RIPA buffer (Biomed, Taiwan), and centrifuged at $13,000 \mathrm{x}$ for $10 \mathrm{~min}$ at $4^{\circ} \mathrm{C}$. The supernatant was used for protein quantification with a Coomassie protein assay reagent (Thermo Fisher Scientific, Inc.). Equal amounts $(15 \mu \mathrm{g} /$ lane $)$ of protein were loaded to each well and separated by SDS-PAGE. Samples were finally transferred to PVDF membrane. Immunoblotting was conducted using the following antibodies: Bcl-2 (cat. no. 15071; Cell Signaling Technology; 1:1,000 dilution), cleaved caspase-3 (cat. no. 9664; Cell Signaling Technology; 1:1,000 dilution), caspase-3 (cat. no. E-AB-30756; Elabscience; 1:1,000 dilution), LC3B (cat. no. 83506; Cell Signaling Technology; 1:1,000 dilution), p62 (cat. no. 5114; Cell Signaling Technology; 1:1,000 dilution), ATG5 (cat. no. E-AB-22149; Elabscience; 1:1,000 dilution), cytochrome $c$ (cat. no. GTX108585; GeneTex; 1:1,500 dilution) and $\beta$-actin (cat. no. E-AB-20034; Elabscience; 1:2,000 dilution), followed by incubation with secondary anti-mouse IgG, HRP-linked antibody (cat. no. 7076P2; Cell Signaling Technology; 1:3,000 dilution) or goat anti-rabbit IgG antibody (cat. no. A0545; Sigma-Aldrich; Merck KGaA; 1:3,000 dilution). Labeled proteins were detected using the ECL Detection Kit (Millipore) by the Alliance Q9 (UVITEC, UK). Normalization was performed with the $\beta$-actin antibody.

T-ALL xenograft murine model. Female NOD/SCID mice, 8 weeks of age and body weight 18 to $22 \mathrm{~g}$, were obtained from the National Laboratory Animal Center. They were housed under specific pathogen-free conditions with at a 12:12-h dark/light cycle with food and water ad libitum, at the Animal Center of Kaohsiung Veterans General Hospital. The study protocol was approved by the Animal Care and Use Committee of Kaohsiung Veterans General Hospital (2020-2021-A031). CCRF-CEM cells ( $1 \times 10^{6}$ cells/100 $\mu \mathrm{l} /$ mouse) suspended in a 1:1 mixture of BD Matrigel $^{\mathrm{TM}}$ (basement membrane matrix, growth factor reduced, phenol red-free; BD Biosciences, cat. no. 356231) and RPMI-1640 medium were injected subcutaneously into the flank region of NOD/SCID mice. Tumor sizes were measured using a digital caliper three times a week until sacrifice. Mice were randomly assigned to different experimental groups ( $\mathrm{n}=5 /$ group) as follows: vehicle control group, $20 \mathrm{mg} / \mathrm{kg}$ of niclosamide treatment group, $5 \mathrm{mg} / \mathrm{kg}$ of niclosamide treatment group and $1 \mathrm{mg} / \mathrm{kg}$ of dexamethasone (DEX) treatment group. Drugs were delivered through intraperitoneal injections, three times a week, starting on day 7 after inducing the xenograft mouse model. Twenty-six days after tumor cell implantation, all mice were anesthetized by sevoflurane (3\%) (Baxter Healthcare Corp.), then they were received $\mathrm{CO}_{2}$ (flow rate: $30 \% / \mathrm{min}$, for $7 \mathrm{~min}$ ) for euthanasia. Tumor tissues were collected for hematoxylin and eosin (H\&E) staining and immunohistochemistry staining.

Hematoxylin and eosin $(H \& E)$ staining. Tumor tissues were removed from the xenograft mice and fixed in $10 \%$ formalin for $24 \mathrm{~h}$ at room temperature. Tissues were then embedded in paraffin and sectioned for staining with hematoxylin and eosin (H\&E). Microscopic images were captured with a light microscope (Olympus BX53).

Immunohistochemistry staining (IHC staining). Tumor tissues were first removed from the xenograft mice. Tumor specimens were fixed in $10 \%$ phosphate-buffered formalin and then dissected and embedded in paraffin. Paraffin sections $(5 \mu \mathrm{m}$ thick) were incubated with $0.3 \%$ hydrogen peroxide for $15 \mathrm{~min}$, blocked for $1 \mathrm{~h}$ at room temperature, and incubated with cleaved caspase-3 (cat. no. 9664; Cell Signaling Technology) and LC3B (cat. no. 83506; Cell Signaling Technology) overnight at $4^{\circ} \mathrm{C}$. After washing with DPBS, sections were processed with the DakoEnVision ${ }^{\circledR}+$ Dual Link System-HRP (DAB+) kit, and immediately stained with DAB (Dako) as required.

Statistical analyses. Data are expressed as mean \pm standard error of mean. Statistical analyses were performed using one-way ANOVA followed by Tukey's test for post-hoc comparisons. Results were analyzed using the software GraphPad Prism (version 6; GraphPad Software, Inc.). $\mathrm{P}<0.05$ was indicative of a statistically significant difference.

\section{Results}

Niclosamide suppresses the viability of T-ALL cells dose-and time-dependently. To investigate the effects of niclosamide on T-ALL cell viability, Jurkat and CCRF-CEM human $\mathrm{T}$ leukemia cells were initially treated with different doses of niclosamide or vehicle control for $24 \mathrm{~h}$. The cytotoxic activity of niclosamide on T-ALL cells was measured with the MTT assays. Results showed that niclosamide ( 0.5 to $4 \mu \mathrm{M})$ exhibited significant cytotoxicity on Jurkat and CCRF-CEM cells and the toxic effects were dose-dependent ( $\mathrm{P}<0.05$; Fig. 1A and $\mathrm{B})$. In addition, the effects of viability of niclosamide were also investigated on Jurkat and CCRF-CEM cells at progressively longer times $(24,48$ and $72 \mathrm{~h})$. The results showed that niclosamide at $2 \mu \mathrm{M}$ significantly reduced the viable numbers of Jurkat cells, and similarly at $1 \mu \mathrm{M}$ in CCRF-CEM cells, both in a time-dependent manner, when compared with the vehicle control ( $\mathrm{P}<0.05$; Fig. $1 \mathrm{C}$ and $\mathrm{D})$. To further investigate the cell proliferation, Ki-67 staining was performed. The results of the Ki-67 analysis showed that niclosamide significantly reduced cell proliferation in Jurkat and CCRF-CEM cells at all doses tested $(\mathrm{P}<0.05$; Fig. $1 \mathrm{E}$ and $\mathrm{F})$. Taken together, the results demonstrated that niclosamide had suppressed the growth of T-ALL cells in a dose- and time-dependent manner.

Niclosamide promotes the apoptosis of T-ALL cells. To further characterize the cell death induced by niclosamide in T-ALL cells, Annexin V-FITC/PI double staining flow cytometry was conducted. Jurkat and CCRF-CEM cells were treated either 

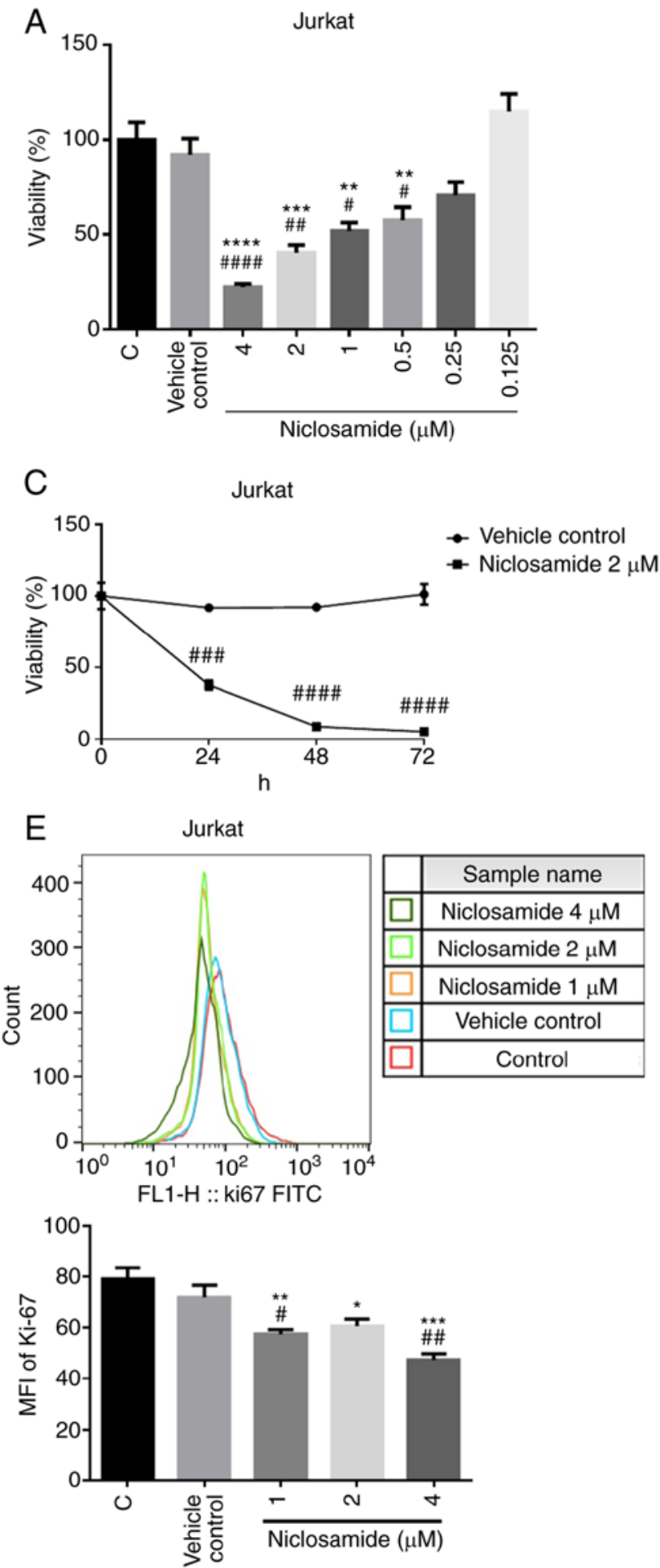

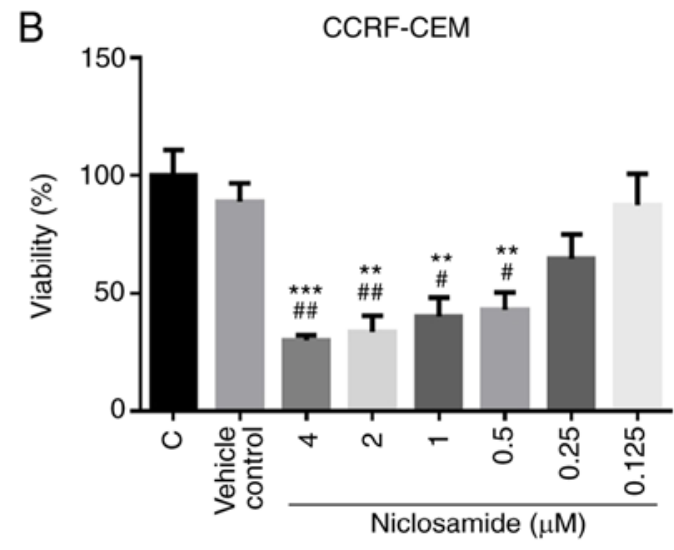

D

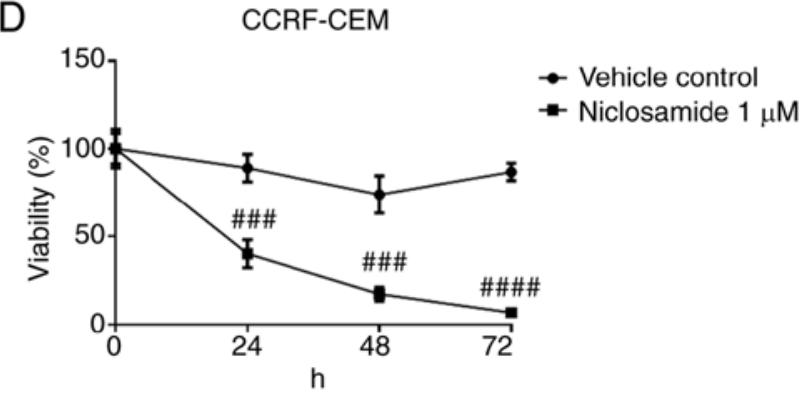

F
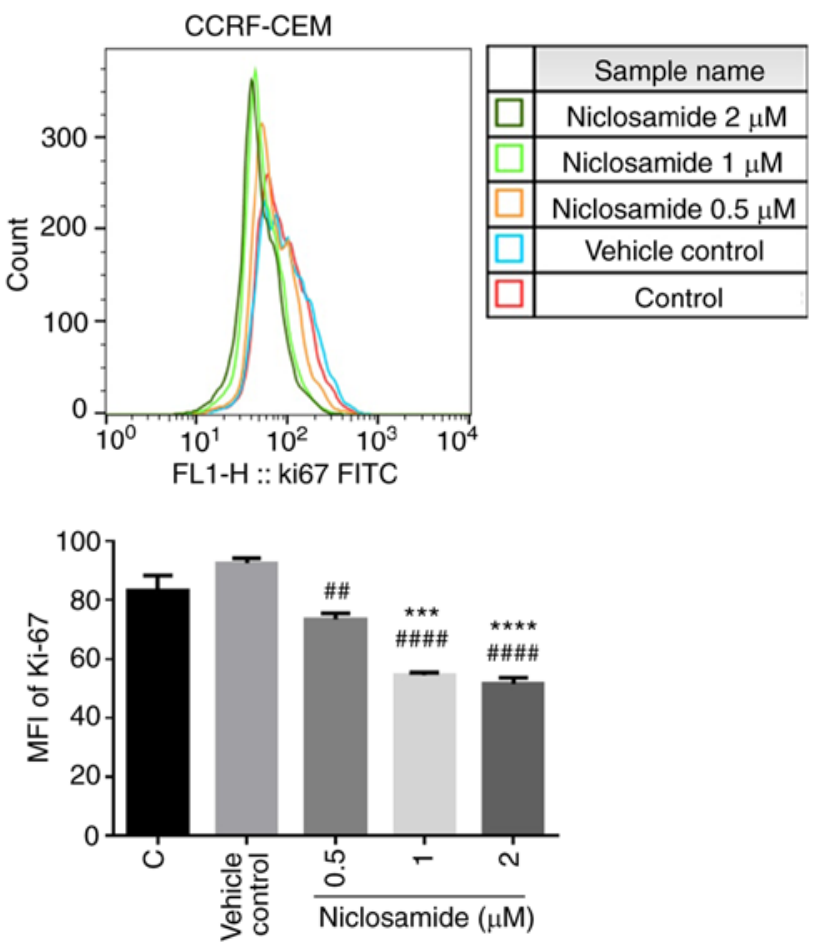

Figure 1. Niclosamide effectively inhibits the viability of T-ALL cells in a dose- and time-dependent manner. Human T-ALL cells were treated with niclosamide for $24 \mathrm{~h}$. Cell viability and proliferation was measured by MTT assays and flow cytometry of Ki-67 staining, respectively. MTT assays showed that niclosamide inhibited the proliferation of (A) Jurkat and (B) CCRF-CEM cells dose-dependently. (C) Jurkat and (D) CCRF-CEM cells were treated with niclosamide for 24, 48 and $72 \mathrm{~h}$. MTT assays showed that niclosamide inhibited the proliferation of Jurkat and CCRF-CEM cells time-dependently. MFI of Ki-67 were examined by flow cytometry after incubation of (E) Jurkat and (F) CCRF-CEM cells treated with different doses of niclosamide for 24 h. Niclosamide treatment effectively inhibited the proliferation of T-ALL cells dose-dependently. The results are expressed as mean $\pm \mathrm{SEM}$. ${ }^{*} \mathrm{P}<0.05,{ }^{* *} \mathrm{P}<0.01,{ }^{* * *} \mathrm{P}<0.001,{ }^{* * * *} \mathrm{P}<0.0001$,

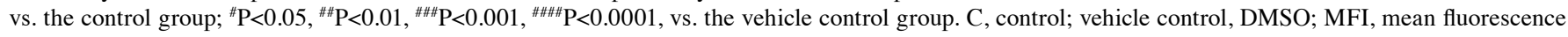
intensity; T-ALL, T-cell acute lymphoblastic leukemia.

with vehicle control (DMSO) or niclosamide for $24 \mathrm{~h}$. Annexin V/PI staining demonstrated that niclosamide at $2 \mu \mathrm{M}$ significantly increased the early and late apoptosis in Jurkat cells, and similarly at $1 \mu \mathrm{M}$ in CCRF-CEM cells ( $\mathrm{P}<0.05$; Fig. 2).
Moreover, apoptosis-related proteins were also assessed. The Jurkat and CCRF-CEM cells treated with different doses of niclosamide for $24 \mathrm{~h}$ were analyzed with western blot analysis. The results showed that the level of $\mathrm{Bcl}-2$ decreased significantly, 

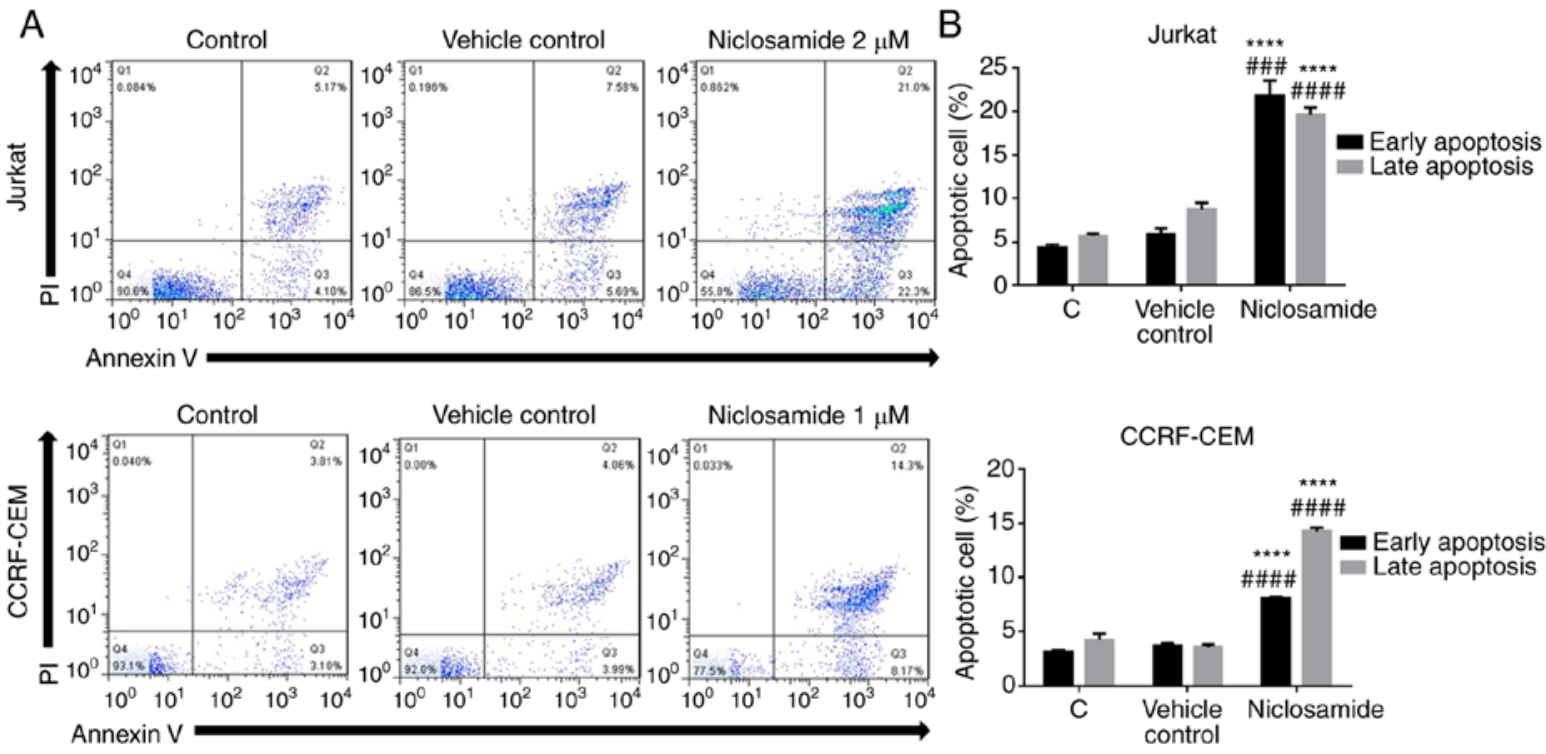

Figure 2. Niclosamide induces apoptosis in T-ALL cells. Jurkat and CCRF-CEM cells were treated with DMSO (vehicle control), and niclosamide for $24 \mathrm{~h}$. (A) Flow cytometric analysis of apoptosis was evaluated by using Annexin V-FITC and PI double staining at $24 \mathrm{~h}$ posterior to the treatment. (B) Quantitative analysis of the apoptotic cells from A. The results are expressed as mean \pm SEM. ${ }^{* * * * *} \mathrm{P}<0.0001$, vs. the control group; ${ }^{\# \# \#} \mathrm{P}<0.001,{ }^{\# \# \# \#} \mathrm{P}<0.0001$, vs. the vehicle control group at $24 \mathrm{~h}$. C, control; vehicle control, DMSO; T-ALL, T-cell acute lymphoblastic leukemia.
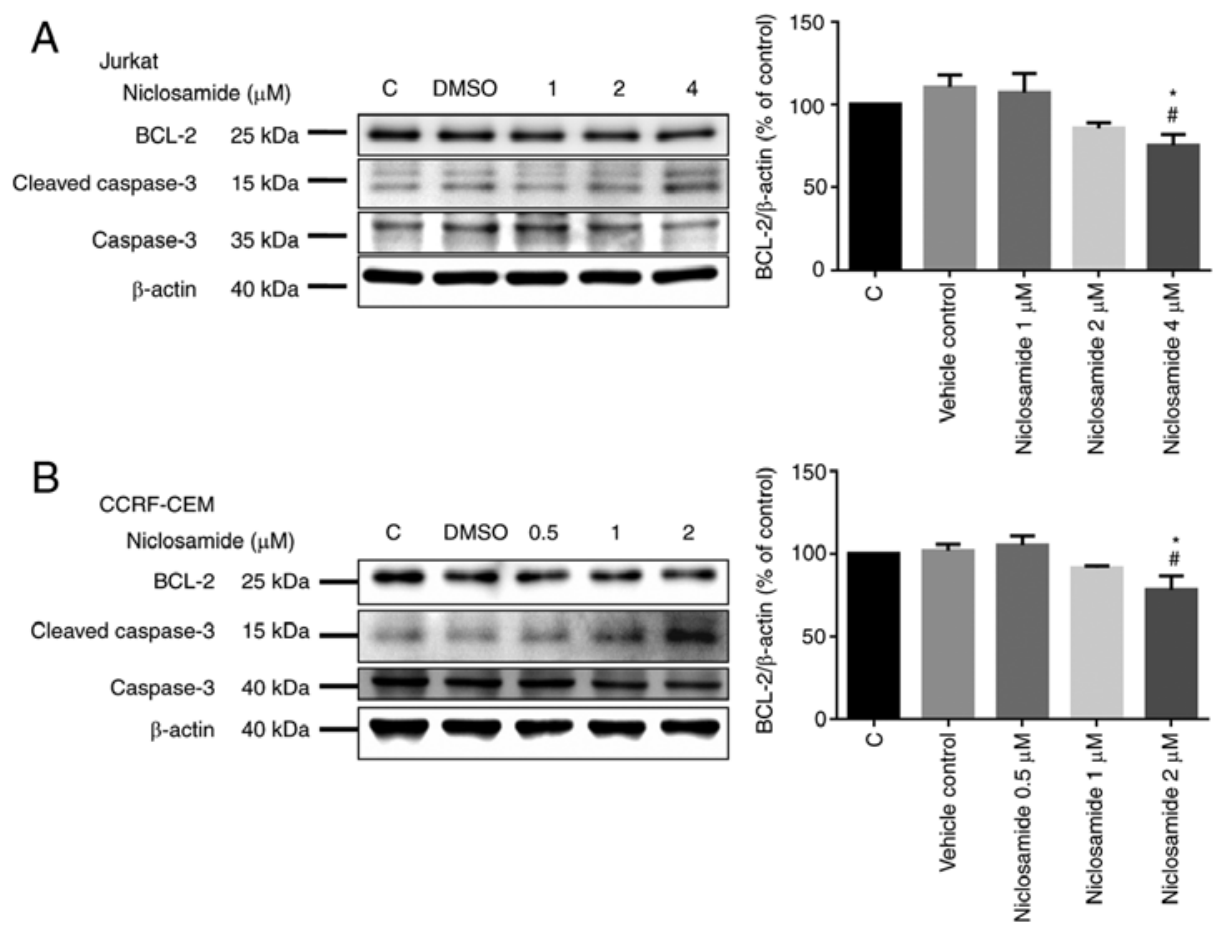
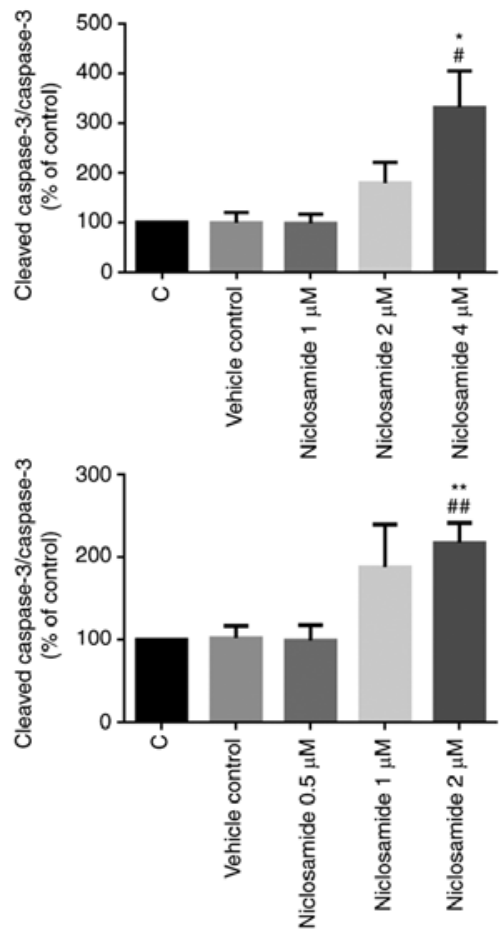

Figure 3. Niclosamide induces T-ALL cell apoptosis in a dose-dependent manner. The cells were treated with different doses of niclosamide for $24 \mathrm{~h}$, and the expression of Bcl-2, cleaved caspase- 3 and caspase- 3 were measured by western blot analysis in (A) Jurkat and (B) CCRF-CEM cells. $\beta$-actin protein was used in these experiments as the loading control. The results are expressed as mean $\pm \mathrm{SEM}$. ${ }^{*} \mathrm{P}<0.05,{ }^{* *} \mathrm{P}<0.01$, vs. the control group; ${ }^{\#} \mathrm{P}<0.05$, ${ }^{\# \#} \mathrm{P}<0.01$, vs. the vehicle control group. C, control; vehicle control, DMSO; T-ALL, T-cell acute lymphoblastic leukemia.

and the level of cleaved caspase-3 increased significantly in a dose-dependent manner after niclosamide treatment for $24 \mathrm{~h}$ in both Jurkat and CCRF-CEM cells ( $\mathrm{P}<0.05$; Fig. 3). According to our findings, there was no significant difference in cytochrome $c$ expression in the cytosolic/mitochondrial ratio, which revealed that niclosamide affects cell apoptosis by non-mitochondrial signaling pathways for the activation of caspases (Fig. S1). Collectively, these findings demonstrated that niclosamide promoted the apoptosis of T-ALL cells in a dose-dependent manner.

Niclosamide induces the autophagy of T-ALL cells. To investigate the role of autophagy induced by niclosamide, Jurkat and CCRF-CEM cells were treated for $24 \mathrm{~h}$ with either vehicle 
A

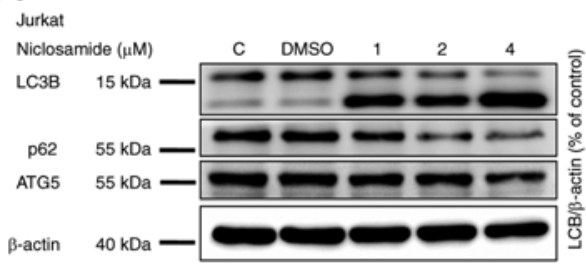

B

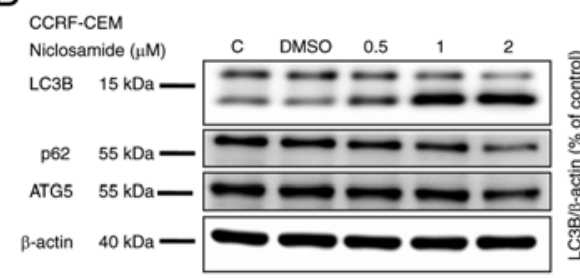

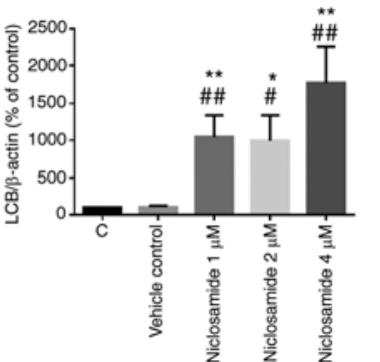

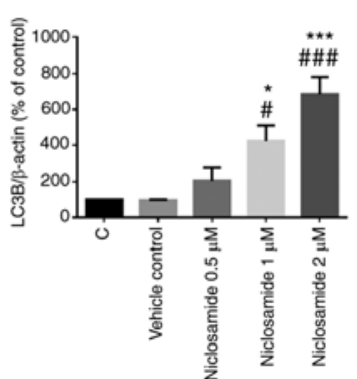

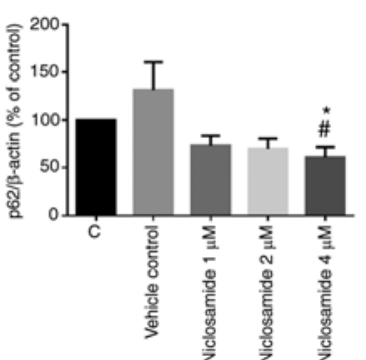
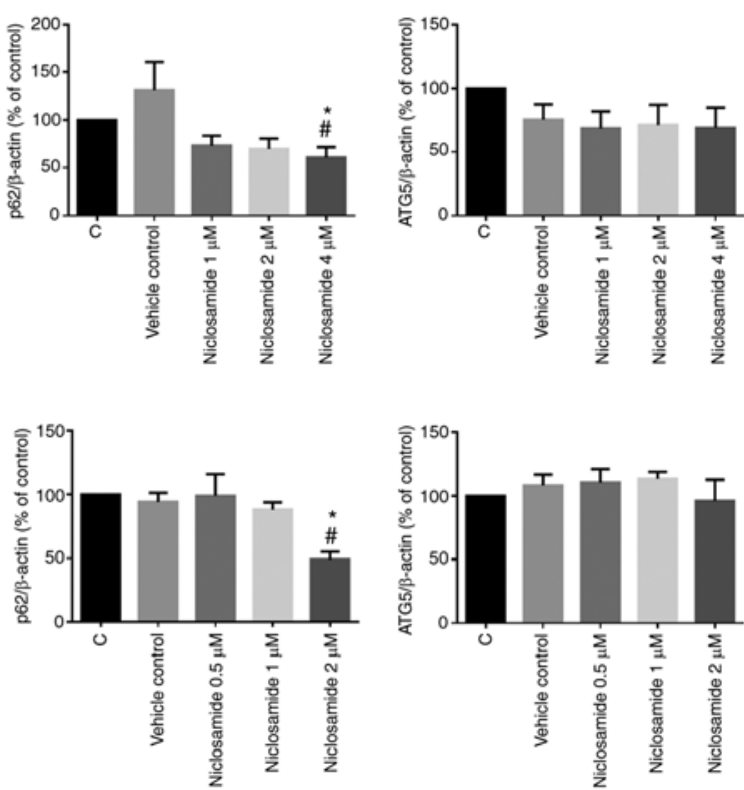

Figure 4. Niclosamide induces T-ALL cell autophagy in a dose-dependent manner. The cells were treated with different doses of niclosamide for $24 \mathrm{~h}$, and the expression of LC3B, p62 and ATG5 were measured by western blot analysis in (A) Jurkat and (B) CCRF-CEM cells. $\beta$-actin protein was used in these experiments as the loading control. The results are expressed as mean \pm SEM. ${ }^{*} \mathrm{P}<0.05,{ }^{* *} \mathrm{P}<0.01,{ }^{* * *} \mathrm{P}<0.001$, vs. the control group; ${ }^{\#} \mathrm{P}<0.05,{ }^{\# \#} \mathrm{P}<0.01,{ }^{\# \# \#} \mathrm{P}<0.001$, vs. the vehicle control group. C, control; vehicle control, DMSO; T-ALL, T-cell acute lymphoblastic leukemia.
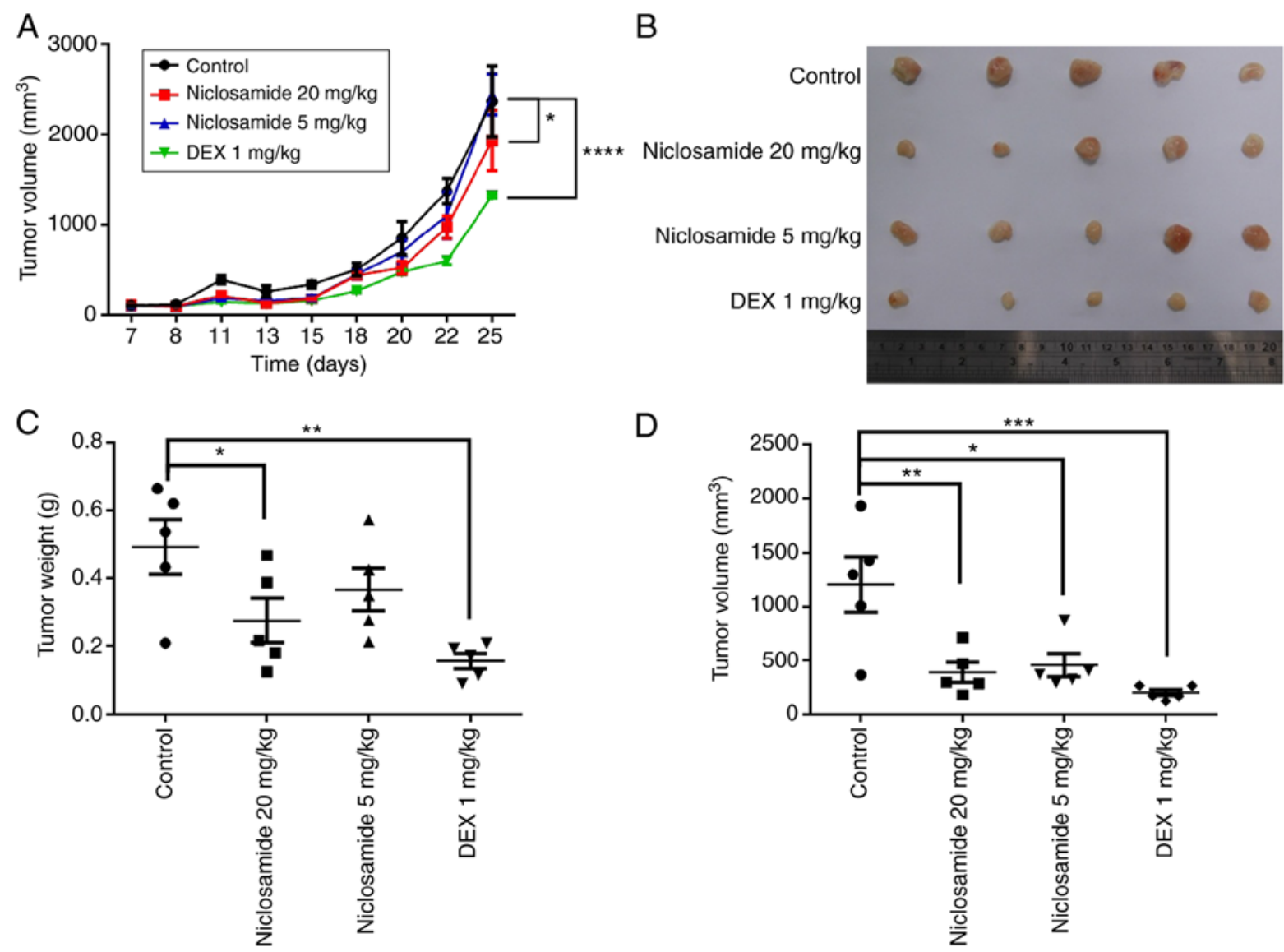

Figure 5. Niclosamide inhibits T-ALL xenograft growth in vivo. (A) NOD/SCID mice bearing CCRF-CEM tumors were randomly separated into four groups: control, 20 and $5 \mathrm{mg} / \mathrm{kg}$ niclosamide treatment, $1 \mathrm{mg} / \mathrm{kg}$ DEX treatment ( $\mathrm{n}=5 /$ group). Tumor volumes were calculated after treatment with niclosamide, normal saline (control) or DEX three times a week for 25 days. (B) The mice were subjected to euthanasia and the tumors from each group were collected and imaged at the end of the experiment. (C) Tumor weights $(\mathrm{F}$ value $=5.332)$ and $(\mathrm{D})$ tumor volume $(\mathrm{F}$ value $=8.968)$ for each group were measured on the last day of the experiment (day 26). The results are expressed as mean \pm SEM. ${ }^{*} \mathrm{P}<0.05,{ }^{* *} \mathrm{P}<0.01,{ }^{* * *} \mathrm{P}<0.001,{ }^{* * * * *} \mathrm{P}<0.0001$, vs. the control group. DEX, dexamethasone; T-ALL, T-cell acute lymphoblastic leukemia. 
A
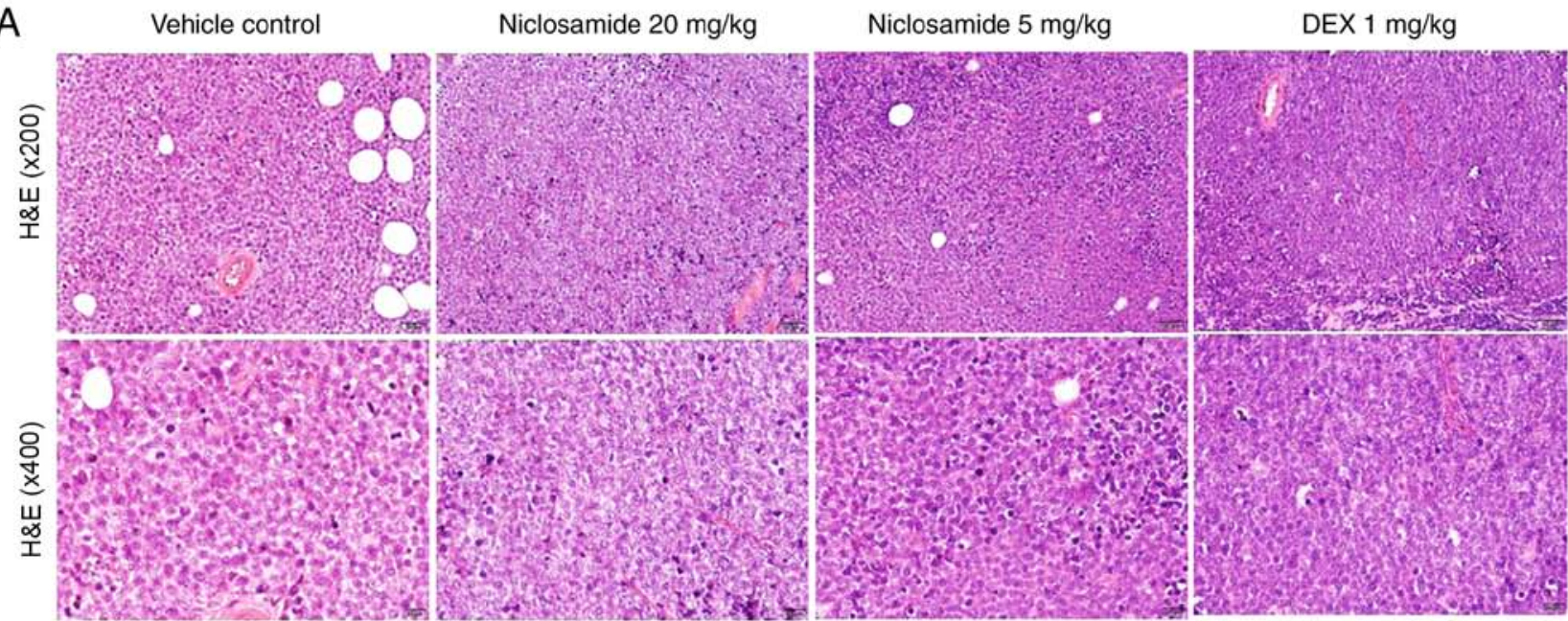

B
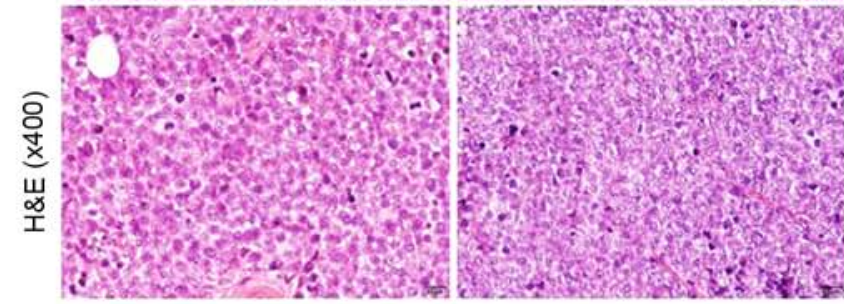

Niclosamide $5 \mathrm{mg} / \mathrm{kg}$

$\mathrm{DEX} 1 \mathrm{mg} / \mathrm{kg}$
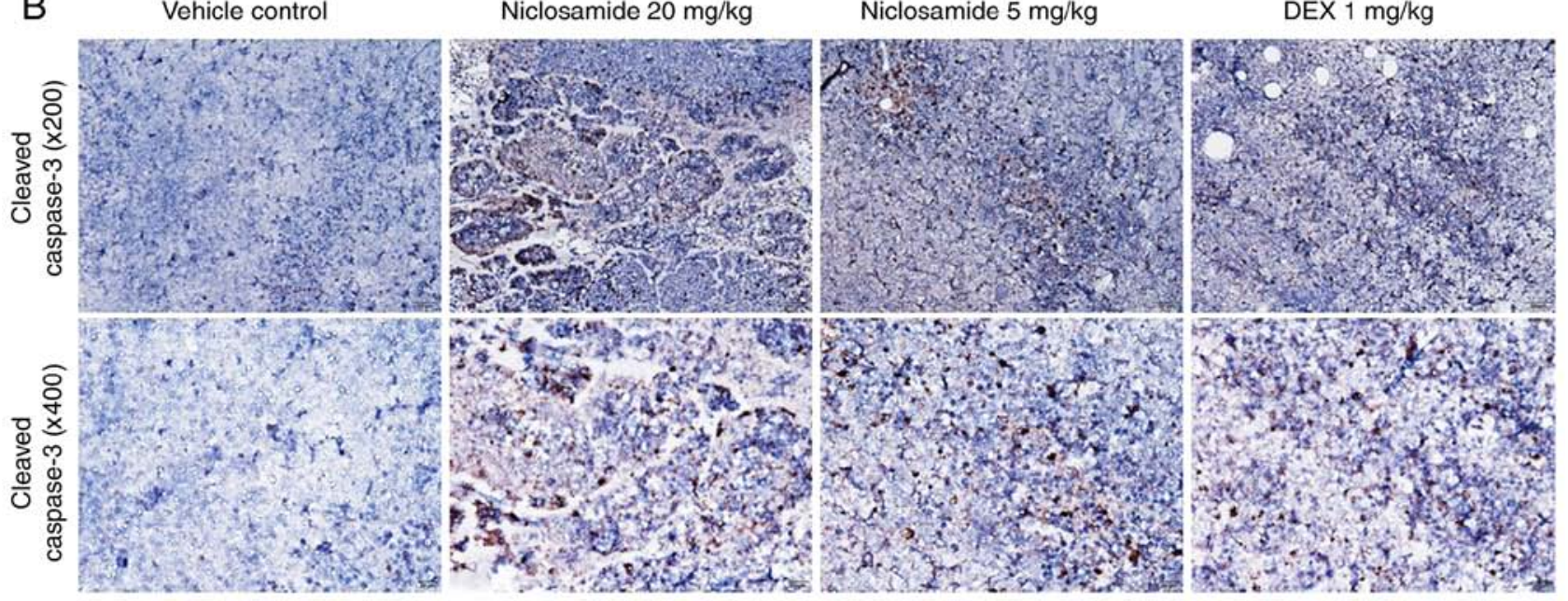

C

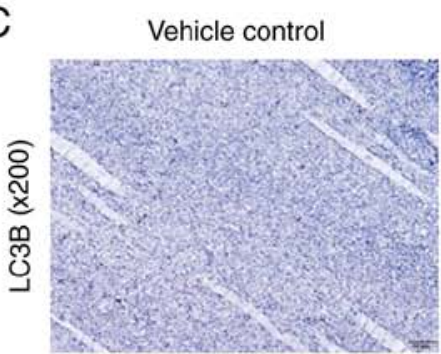

Niclosamide $20 \mathrm{mg} / \mathrm{kg}$

Niclosamide $5 \mathrm{mg} / \mathrm{kg}$

$\mathrm{DEX} 1 \mathrm{mg} / \mathrm{kg}$
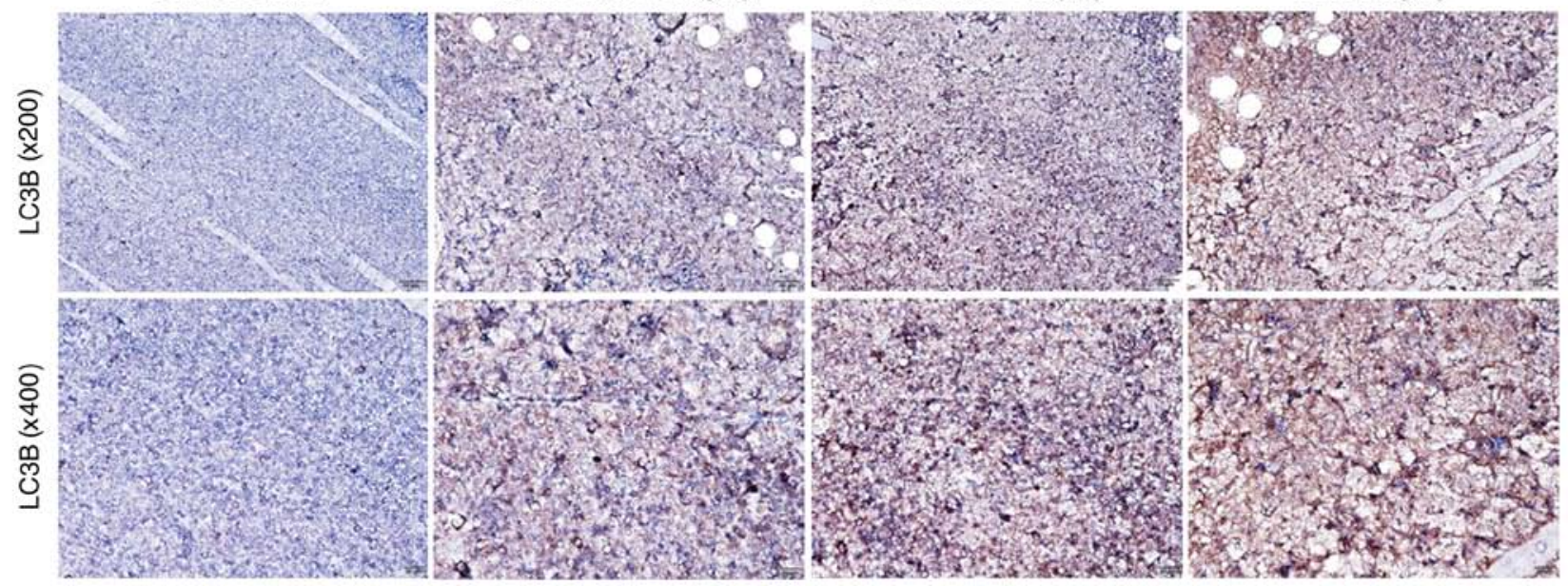

Figure 6. Niclosamide suppresses xenograft tumor proliferation and promotes the production of cleaved caspase-3 and LC3B in NOD/SCID mice. Tumor samples were subjected to (A) H\&E staining and IHC analysis for (B) cleaved caspase-3 and (C) LC3B at the end of the experiment. Slides were scanned on magnifications of x 200 and x400. H\&E, hematoxylin and eosin; IHC, immunohistochemistry.

control (DMSO) or niclosamide at different doses. We found that the level of Microtubule Associated Protein 1 Light Chain $3 \beta$ (LC3B) was increased significantly and the level of p62 was decreased significantly in a dose-dependent manner after niclosamide treatment in both Jurkat and CCRF-CEM cells. But we found no change in the level of Autophagy Related 5
(ATG5) (Fig. 4). Taken together, the results demonstrated that niclosamide activated autophagy in T-ALL cells in a dose-dependent manner.

Niclosamide suppresses CCRF-CEM leukemia cell growth in an in vivo xenograft mouse model. To confirm the in vitro 
results, the antitumor effects of niclosamide in vivo were investigated by measuring its effects in the CCRF-CEM xenograft murine model. CCRF-CEM cells were subcutaneously injected into NOD/SCID mice for 26 days and treated with either 5 or $20 \mathrm{mg} / \mathrm{kg}$ of niclosamide, or $1 \mathrm{mg} / \mathrm{kg}$ of dexamethasone three times a week. The results showed that mice treated with niclosamide $(20 \mathrm{mg} / \mathrm{kg}$ ) and dexamethasone had significantly attenuated tumor growth compared with the controls $(\mathrm{P}<0.05$; Fig. 5A). At the end of the study, tumors were isolated from the mice and weighed. The overall weight and volume of the tumors in the niclosamide-treated group and dexamethasone-treated group were significantly lower than those of the controls $(\mathrm{P}<0.05$; Fig. 5B-D). After 26 days, the mean tumor weight in the niclosamide-treated group $(20 \mathrm{mg} / \mathrm{kg})$ was $0.2756 \pm 0.06513 \mathrm{~g}$, and in the dexamethasone-treated group was $0.1562 \pm 0.02282 \mathrm{~g}$, both were significantly lower than the controls $(0.4934 \pm 0.08122 \mathrm{~g})(\mathrm{P}<0.05$; Fig. 5C). The mean tumor volume in the niclosamide-treated group $(20 \mathrm{mg} / \mathrm{kg})$ was $392.8 \pm 92.49 \mathrm{~mm}^{3}$, in the niclosamide-treated group $(5 \mathrm{mg} / \mathrm{kg})$ was $458.4 \pm 106.2 \mathrm{~mm}^{3}$, and in the dexamethasone-treated group was $202.9 \pm 29.08 \mathrm{~mm}^{3}$, all statistically significantly smaller than the controls $\left(1,206 \pm 257.0 \mathrm{~mm}^{3}\right)(\mathrm{P}<0.05$; Fig. 5D). The survival rates of all the mouse groups were $100 \%$ (Fig. S2). Therefore, the in vivo results showed that niclosamide inhibited CCRF-CEM leukemia cell tumor growth.

Niclosamide activates apoptosis and autophagy proteins in the CCRF-CEM leukemia cell xenograft mouse model. To investigate the effects of niclosamide on apoptosis- and autophagy-related proteins, tumors from the CCRF-CEM leukemia cells xenograft mouse model were collected for $\mathrm{H} \& \mathrm{E}$ staining and immunohistochemical analysis. H\&E staining showed that tumor masses contained leukemia cells, with a discohesive pattern of medium to large atypical lymphoid cells showing brisk apoptosis and mitotic activities (Fig. 6A). Immunohistochemical analyses showed that CCRF-CEM leukemia cell xenograft mice treated with niclosamide (5 and $20 \mathrm{mg} / \mathrm{kg})$ and DEX $(1 \mathrm{mg} / \mathrm{kg})$ exhibited markedly increased expressions of both cleaved caspase-3 and LC3B compared with the vehicle controls (Fig. 6B and C).

\section{Discussion}

Our present study is the first to report that niclosamide effectively inhibits the growth of T-cell acute lymphoblastic leukemia (T-ALL). Specifically, we analyzed the effects of niclosamide treatment on apoptosis and autophagy in T-ALL cells and in the xenograft mouse model. The results showed that niclosamide inhibited the viability of T-ALL cells in a dose- and time-dependent manner. Furthermore, we demonstrated that niclosamide effectively inhibited the viability of T-ALL cells and tumor growth through activating apoptosis and autophagy.

Niclosamide is an anti-helminthic agent approved by the FDA. Previous studies have reported that niclosamide exhibits anticancer activity by regulating the apoptotic pathways. Our present results of niclosamide, regarding its suppression of ALL cell viability via inducing apoptotic cell death, agree with earlier reports that niclosamide induces apoptosis in various cancer types, such as chronic myeloid leukemia (21), breast cancer (22) and adrenocortical carcinoma (23). In the present study, niclosamide exhibited anticancer effects by upregulation of cleaved caspase- 3 and downregulation of Bcl-2. According to our findings, niclosamide did not affect expression of cytochrome $c$ (Fig. S1). The amount of cytochrome $c$ expression fluctuates with different times (24). Therefore, our findings showed that niclosamide affects cell apoptosis by non-mitochondrial signaling pathways for activation of caspases.

In tumorigenesis, the role of autophagy as a tumor suppressor or tumor promoter remains controversial. During autophagy, p62 binds to LC3 to promote the degradation of ubiquitinated cell organisms (25). High levels of p62 in human acute myeloid leukemia are associated with a poor prognosis (26). Induction of autophagy by rapamycin has effects of anti-leukemia in ALL (27). Therefore, all of these findings indicate that autophagy has tumor-suppressive effects. In contrast, other studies have reported that autophagy has tumor-promoter action. Autophagy driven by genes or by pharmacological inhibition was found to induce leukemia cell death $(28,29)$. What is the role of autophagy in niclosamide-treated T-ALL cells? In the present study, niclosamide treatment increased LC3B expression and decreased p62 expression, leading to T-ALL cell death. Our results are in line with previous studies. Increased autophagy could cause leukemia cell death. Niclosamide was found to induce apoptosis and autophagic cell death by regulating mitochondria dynamics (30). Induction of apoptosis and autophagy both are known to cause T-ALL cell death. For example, tamoxifen treatment was found to induce apoptosis and autophagy in Jurkat cells (31). Previous studies have indicated that Bcl-2 family members regulate autophagy. Bcl-2 family members inhibit autophagy regulator beclin 1, which limits the formation of autophagosome and inhibits autophagy $(32,33)$. In human HL60 cells, downregulation of Bcl-2 was found to induce autophagy without impairing the mitochondrial functions (34). Therefore, this evidence indicates that Bcl-2 exerts an inhibitory effect on autophagy. This evidence is consistent with our findings. Niclosamide inhibited the expression of Bcl-2 and induced autophagy by regulating the formation of autophagosomes. Therefore, the present study showed that apoptosis and autophagy are both activated by niclosamide, leading to the death of T-ALL cells, both in vitro and in vivo.

Most current leukemia studies have adopted the xenograft mouse model by subcutaneously injecting tumor cells, followed by measuring the volume and weight of the subcutaneous tumors. Other xenograft mouse models use intravenous injection of tumor cells. The number of tumor cells in the body after drug treatment are evaluated by IVIS imaging to determine effects of treatment. In the present study, we used the T-ALL xenograft mouse model by subcutaneously injecting leukemia cells to evaluate the effect of niclosamide treatment. Our study showed that niclosamide effectively inhibited tumor growth in the T-ALL xenograft mice. Pathological analyses showed that niclosamide treatment caused an increase in pro-apoptosis marker cleaved caspase-3 and autophagy marker LC3B. Most studies, including our present one, with subcutaneous tumor cell 
injection in leukemia xenograft mice all adopted volume and weight measurements of tumors to evaluate tumor growth $(35,36)$.

There are some limitations to the present study. First, we observed that niclosamide activated apoptosis and autophagy in T-ALL cells both in vitro and in vivo, but there was no direct evidence to confirm that the inhibition of autophagy affected apoptosis. To verify the relationship between autophagy and apoptosis, one may need to use siRNA. Second, the present study did not use clinical samples for further verification. There are patients with a type of relapsed/refractory T-ALL that are difficult to treat. In the future, other T-ALL patients should be further investigated to ascertain whether niclosamide can be their effective treatment.

In conclusion, the effects of niclosamide treatment were assessed on T-ALL cells and in a T-ALL xenograft mouse model. The results showed that niclosamide has the potential for suppressing T-ALL cell viability in vitro, and in suppressing tumor growth in T-ALL xenograft mice in vivo, both by activating the apoptosis and autophagy pathways. Our findings provide new insight into the application of niclosamide for T-ALL treatment.

\section{Acknowledgements}

We thank Dr Wen-Long Cho (Institute of Biomedical Sciences, MacKay Medical College, Sanzhi, New Taipei City, Taiwan, R.O.C.) for his suggestion for our experimental design. We thank Dr Ren-Ching Wang (Department of Pathology and Laboratory Medicine, Taichung Veterans General Hospital, Taichung, Taiwan, R.O.C.) for providing assistance in the H\&E staining analysis.

\section{Funding}

The present work was supported by grants from Taichung Veterans General Hospital (TCVGH-NCHU1097611, TCVGH-NCHU1107609 and TCVGH-1106503C) and Ministry of Science and Technology (MOST 110-2314-B-075A-002).

\section{Availability of data and materials}

The datasets used during the present study are available from the corresponding author upon reasonable request.

\section{Authors' contributions}

FLH, SJY and CLL designed the experiments. FLH, SJY and CLL performed the experiments and the statistical analyses for the molecular biology experimental results. ECL, LYL and PWS acquired and analyzed the data. FLH, SJY and CLL drafted the initial manuscript. FLH and CLL confirmed the authenticity of all the raw data. All authors have read and approved the final manuscript.

\section{Ethics approval and consent to participate}

The study protocol for the mouse xenograft experiment was approved by the Animal Care and Use Committee of Kaohsiung Veterans General Hospital (2020-2021-A031).

\section{Patient consent for publication}

Not applicable.

\section{Competing interests}

The authors declare no competing interests.

\section{References}

1. Arber DA, Orazi A, Hasserjian R, Thiele J, Borowitz MJ, Le Beau MM, Bloomfield CD, Cazzola M and Vardiman JW: The 2016 revision to the World Health Organization classification of myeloid neoplasms and acute leukemia. Blood 127: 2391-2405, 2016.

2. Terwilliger T and Abdul-Hay M: Acute lymphoblastic leukemia: A comprehensive review and 2017 update. Blood Cancer J 7: e577, 2017.

3. Karrman K and Johansson B: Pediatric T-cell acute lymphoblastic leukemia. Genes Chromosomes Cancer 56: 89-116, 2017.

4. Corella Aznar EG, Ayerza Casas A, Carboné Bañeres A, Calvo Escribano MÁC, Labarta Aizpún JI and Samper Villagrasa P: Quality of life and chronic health conditions in childhood acute leukaemia survivors. Med Clin (Barc) 152: 167-173, 2019.

5. Singh SK, Banerjee S, Acosta EP, Lillard JW and Singh R: Resveratrol induces cell cycle arrest and apoptosis with docetaxel in prostate cancer cells via a p53/p21WAF1/CIP1 and p27KIP1 pathway. Oncotarget 8: 17216-17228, 2017.

6. Cai Y, Xia Q, Su Q, Luo R, Sun Y, Shi Y and Jiang W: mTOR inhibitor RAD001 (everolimus) induces apoptotic, not autophagic cell death, in human nasopharyngeal carcinoma cells. Int J Mol Med 31: 904-912, 2013.

7. Ciombor KK and Bekaii-Saab T: Selumetinib for the treatment of cancer. Expert Opin Investig Drugs 24: 111-123, 2015.

8. Huang FL, Liao EC, Li CL, Yen CY and Yu SJ: Pathogenesis of pediatric B-cell acute lymphoblastic leukemia: Molecular pathways and disease treatments (Review). Oncol Lett 20: 448-454, 2020.

9. Al-Hadiya BM: Niclosamide: Comprehensive profile. Profiles Drug Subst Excip Relat Methodol 32: 67-96, 2005.

10. Merschjohann K and Steverding D: In vitro trypanocidal activity of the anti-helminthic drug niclosamide. Exp Parasitol 118: 637-640, 2008.

11. Hogarth LA and Hall AG: Increased BAX expression is associated with an increased risk of relapse in childhood acute lymphocytic leukemia. Blood 93: 2671-2678, 1999.

12. Chen W, Mook RA Jr, Premont RT and Wang J: Niclosamide: Beyond an antihelminthic drug. Cell Signal 41: 89-96, 2018.

13. Zhu Y, Zuo W, Chen L, Bian S, Jing J, Gan C, Wu X, Liu H, $\mathrm{Su} \mathrm{X}, \mathrm{Hu}$, et al: Repurposing of the anti-helminthic drug niclosamide to treat melanoma and pulmonary metastasis via the STAT3 signaling pathway. Biochem Pharmacol 169: 113610, 2019.

14. Liao Z, Nan G, Yan Z, Zeng L, Deng Y, Ye J, Zhang Z, Qiao M, Li R, Denduluri S, et al: The anthelmintic drug niclosamide inhibits the proliferative activity of human osteosarcoma cells by targeting multiple signal pathways. Curr Cancer Drug Targets 15: 726-738, 2015.

15. Mathew R, Kongara S, Beaudoin B, Karp CM, Bray K, Degenhardt K, Chen G, Jin S and White E: Autophagy suppresses tumor progression by limiting chromosomal instability. Genes Dev 21: 1367-1381, 2007.

16. Mathew R, Karp CM, Beaudoin B, Vuong N, Chen G, Chen HY, Bray K, Reddy A, Bhanot G, Gelinas C, et al: Autophagy suppresses tumorigenesis through elimination of p62. Cell 137: 1062-1075, 2009.

17. Teuffel O, Kuster SP, Hunger SP, Conter V, Hitzler J, Ethier MC, Shah PS, Beyene J and Sung L: Dexamethasone versus prednisone for induction therapy in childhood acute lymphoblastic leukemia: A systematic review and meta-analysis. Leukemia 25: 1232-1238, 2011.

18. Bhadri VA, Trahair TN and Lock RB: Glucocorticoid resistance in paediatric acute lymphoblastic leukaemia. J Paediatr Child Health 48: 634-640, 2012.

19. Wang H, Dong R, Fan WW, Zheng XC, Li AM and Wang WD: Timosaponin AIII induces autophagy of Tcell acute lymphoblastic leukemia Jurkat cells via inhibition of the PI3K/Akt/mTOR pathway. Oncol Rep 41: 2937-2944, 2019. 
20. Wang J, Ren XR, Piao H, Zhao S, Osada T, Premont RT, Mook RA Jr, Morse MA, Lyerly HK and Chen W: Niclosamide-induced Wnt signaling inhibition in colorectal cancer is mediated by autophagy. Biochem J 476: 535-546, 2019.

21. Jin B, Wang C, Shen Y and Pan J: Anthelmintic niclosamide suppresses transcription of BCR-ABL fusion oncogene via disabling Sp1 and induces apoptosis in imatinib-resistant CML cells harboring T315I mutant. Cell Death Dis 9: 68, 2018.

22. Lu L, Dong J, Wang L, Xia Q, Zhang D, Kim H, Yin T, Fan S and Shen Q: Activation of STAT3 and Bcl-2 and reduction of reactive oxygen species (ROS) promote radioresistance in breast cancer and overcome of radioresistance with niclosamide. Oncogene 37: 5292-5304, 2018.

23. Satoh K, Zhang L, Zhang Y, Chelluri R, Boufraqech M, Nilubol N, Patel D, Shen M and Kebebew E: Identification of niclosamide as a novel anticancer agent for adrenocortical carcinoma. Clin Cancer Res 22: 3458-3466, 2016.

24. Krause $M$ and Durner J: Harpin inactivates mitochondria in Arabidopsis suspension cells. Mol Plant Microbe Interact 17: 131-139, 2004.

25. Liu WJ, Ye L, Huang WF, Guo LJ, Xu ZG, Wu HL, Yang C and Liu HF: p62 links the autophagy pathway and the ubiqutin-proteasome system upon ubiquitinated protein degradation. Cell Mol Biol Lett 21: 29, 2016

26. Nguyen TD, Shaid S, Vakhrusheva O, Koschade SE, Klann K, Thölken M, Baker F, Zhang J, Oellerich T, Sürün D, et al: Loss of the selective autophagy receptor p62 impairs murine myeloid leukemia progression and mitophagy. Blood 133: 168-179, 2019.

27. Gong Y, Wu J, Yang R, Zhang L and Ma Z: Rapamycin-induced autophagy plays a pro-survival role by enhancing up-regulation of intracellular ferritin expression in acute lymphoblastic leukemia. Exp Oncol 42: 11-15, 2020.

28. Rothe K, Lin H, Lin KB, Leung A, Wang HM, Malekesmaeili M, Brinkman RR, Forrest DL, Gorski SM and Jiang X: The core autophagy protein ATG4B is a potential biomarker and therapeutic target in CML stem/progenitor cells. Blood 123: 3622-3634, 2014.
29. Baquero P, Dawson A, Mukhopadhyay A, Kuntz EM, Mitchell R, Olivares O, Ianniciello A, Scott MT, Dunn K, Nicastri MC, et al: Targeting quiescent leukemic stem cells using second generation autophagy inhibitors. Leukemia 33: 981-994, 2019.

30. Park SJ, Shin JH, Kang H, Hwang JJ and Cho DH: Niclosamide induces mitochondria fragmentation and promotes both apoptotic and autophagic cell death. BMB Rep 44: 517-522, 2011.

31. Torres-López L, Maycotte P, Liñán-Rico A, Liñán-Rico L, Donis-Maturano L, Delgado-Enciso I, Meza-Robles C, Vásquez-Jiménez C, Hernández-Cruz A and Dobrovinskaya O: Tamoxifen induces toxicity, causes autophagy, and partially reverses dexamethasone resistance in Jurkat T cells. J Leukoc Biol 105: 983-998, 2019.

32. Chong SJF, Marchi S, Petroni G, Kroemer G, Galluzzi L and Pervaiz S: Noncanonical cell fate regulation by Bcl-2 proteins. Trends Cell Biol 30: 537-555, 2020.

33. Pattingre S, Tassa A, Qu X, Garuti R, Liang XH, Mizushima N, Packer M, Schneider MD and Levine B: Bcl-2 antiapoptotic proteins inhibit Beclin 1-dependent autophagy. Cell 122: 927-939, 2005.

34. Saeki K, Yuo A, Okuma E, Yazaki Y, Susin SA, Kroemer G and Takaku F: Bcl-2 down-regulation causes autophagy in a caspase-independent manner in human leukemic HL60 cells. Cell Death Differ 7: 1263-1269, 2000.

35. Ge C, Huang H, Huang F, Yang T, Zhang T, Wu H, Zhou H, Chen Q, Shi Y, Sun Y, et al: Neurokinin-1 receptor is an effective target for treating leukemia by inducing oxidative stress through mitochondrial calcium overload. Proc Natl Acad Sci USA 116: 19635-19645, 2019.

36. Yang L, Li M, Wang F, Zhen C, Luo M, Fang X, Zhang H, Zhang J, $\mathrm{Li} \mathrm{Q}$ and $\mathrm{Fu} \mathrm{L}$ : Ceritinib enhances the efficacy of substrate chemotherapeutic agent in human ABCB1-Overexpressing leukemia cells in vitro, in vivo and ex-vivo. Cell Physiol Biochem 46: 2487-2499, 2018.

\footnotetext{
This work is licensed under a Creative Commons Attribution-NonCommercial-NoDerivatives 4.0 International (CC BY-NC-ND 4.0) License.
} 